\title{
Performance and Mechanism of Layered Double Hydroxide to Remove Graphene Oxide in Aqueous Solution
}

\author{
Haibo Kang*, Jiahui Gu*, Gang Liu**, Ben li* and Wei Wang*† \\ *School of Civil Engineering, Shaoxing University, Shaoxing, Zhejiang, P. R. China \\ **School of Architecture and Civil Engineering, Jiangsu University of Science and Technology, Zhenjiang, P. R. China \\ $\dagger$ Corresponding author: Wei Wang; wellswang@usx.edu.cn
}

Nat. Env. \& Poll. Tech.

Website: www.neptjournal.com

Received: 09-07-2020

Revised: $09-09-2020$

Accepted: 16-09-2020

Key Words:

Graphene oxide

Layered double hydroxide

Wastewater

Adsorption

\begin{abstract}
Intending to remove toxic graphene oxide (GO) from wastewater, LDH (layered double hydroxide) was employed to recover GO by adsorption method. The adsorption performance and the mechanism of LDH for GO have been systematically studied by diverse characterization technologies and methods. The relevant effects of solution $\mathrm{pH}(2-9)$, absorbent dosage $(5-25 \mathrm{mg})$ and the concentration of GO $(20-160 \mathrm{mg} / \mathrm{L})$ were investigated in detail. The main driving force of GO condensation on LDH may be electrostatic interaction and hydrogen bonding, SEM, TEM, AFM, FT-IR and XRD analysis further confirmed this. XPS test shows that the adsorption process is carried out through $\mathrm{C}-\mathrm{O}$ and $\mathrm{O}-\mathrm{C}=\mathrm{O}$. We have got a high removal rate of $92 \%$ and an adsorption capacity of $1472 \mathrm{mg} / \mathrm{g}$ under an optimized conditions $\left(\mathrm{pH}=3.0\right.$, equilibrium time $=6.0 \mathrm{~h}$, dosage $\left.=10 \mathrm{mg}, \mathrm{C}_{0}=160 \mathrm{mg} / \mathrm{L}\right)$. The analyses implied that $\mathrm{LDH}$ will be a very promising candidate for recovery of $\mathrm{GO}$ from wastewater.
\end{abstract}

\section{INTRODUCTION}

Graphene oxide (GO) is synthesized by the oxidation of two-dimensional carbon allotrope graphene, known for its extraordinary specific surface area and abundant $\mathrm{O}$-containing functional groups (such as $-\mathrm{COOH}$ and $-\mathrm{OH}$ ). GO shows great potential in multi-disciplinary fields such as medical, energy, environmental pollution (Azadian et al. 2020, Baragaño et al. 2020, Wu et al. 2020). Particularly, these characteristics provide graphene oxide with many adsorption sites for various heavy metal ions and organic pollutants (Awad et al. 2020, Duru et al. 2016, Xing et al. 2020). For example, magnetic GO composite materials have been synthesized and used to remove $\mathrm{Cd}$ (II) and $\mathrm{Pb}$ (II) from aqueous solutions (Bao et al. 2020). A graphene oxide/bentonite-loaded nano-iron synthesized by liquid-phase redox method was used to treat lead-contaminated water (Yu et al. 2020). Continuously photocatalytic removal of chromium (VI) reduced graphene oxide microspheres (Liu et al. 2020) by using structured porous $\mathrm{Ag} / \mathrm{Ag}_{3} \mathrm{PO}_{4}$.

Although GO and GO-based nanomaterials have been widely used as adsorbents for clean environmental pollution, GO will inevitably be released into the environment and ecosystems, including surface water and groundwater (Zhang et al. 2020). Once in natural and drinking water, GO may undergo physical and chemical changes due to exposure to sunlight and chlorination disinfection, respectively. Besides, the transformation of GO under light leads to the increase of toxicity of GO to biological cells (Gao et al. 2019). Because of these potential negative risks associated with GO, it is important to remove GO during drinking and wastewater treatment. Besides, in mammals, GO exposure may lead to lung or reproductive toxicity (Liang et al. 2015. Yang et al. 2013a), exposure to GO may have adverse effects on organisms, such as fish and shrimp (Batista de Melo et al. 2019, Paital et al. 2019).

Generally, layered double hydroxide (LDH) adopts an anionic layered structure like hydrotalcite, which is assembled through a non-covalent bond interaction between the cationic host layer and the anion guest intermediate layer (Pang et al. 2019). LDH materials can be expressed according to the general formula $\left[\mathrm{M}_{1-\mathrm{p}}^{2+} \mathrm{M}_{\mathrm{p}}^{3+}(\mathrm{OH})_{2}\right]^{\mathrm{p}+}\left[\left(\mathrm{A}^{\mathrm{q}-}\right)_{\mathrm{p} / \mathrm{q}}\right]$ ${ }^{\mathrm{p}-}$. $\mathrm{y} \mathrm{H}_{2} \mathrm{O}$, in which $\mathrm{M}^{2+}$ and $\mathrm{M}^{3+}$ represent bi-/trivalent metal cations $\left(\mathrm{Mg}^{2+}, \mathrm{Ca}^{2+}, \mathrm{Ni}^{2+}, \mathrm{Al}^{3+}\right.$ and $\left.\mathrm{Fe}^{3+}\right), \mathrm{A}^{\mathrm{q}-}$ represents non-framework (in)organic q-valent interlayer anions $\left(\mathrm{NO}_{3}^{-}, \mathrm{ClO}_{4}^{-}\right.$, and $\left.\mathrm{SO}_{4}{ }^{2-}\right)$, $\mathrm{p}$ denotes the molar ratio of $\mathrm{M}^{2+}$ / $\left(\mathrm{M}^{2+}+\mathrm{M}^{3+}\right)$, and $y$ denotes the molar amount of intercalated water. Due to its special structural advantages, such as larger interlayer spacing, wider chemical composition, and ion exchange capacity, LDH materials are widely used as catalysts or adsorbents in the field of water remediation (Song et al. 2018, Wang et al. 2016, Wang et al. 2018, Yang et al. 2017, Yu et al. 2017). Compared with conventional flocculants, LDHs can be produced from the natural 
environment and can aggregate with nanomaterials, which can form target stable complexes in aqueous solutions and form new minerals (secondary minerals). However, as far as we know, there are few studies on the interaction between $\mathrm{GO}$ and $\mathrm{LDH}$ in aqueous solution. This knowledge is very important to improve the surface condensation/precipitation model and to better assess the environmental fate of toxic GO nanomaterials.

In this work, LDH was used as an adsorbent to remove $\mathrm{GO}$ from aqueous solutions. Environmental conditions such as $\mathrm{pH}, \mathrm{LDH}$ content, and initial GO concentration were studied to evaluate the removal performance in detail. X-ray diffraction (XRD), Fourier transform infrared spectroscopy (FT-IR), scanning electron microscope (SEM), transmission electron microscope (TEM), atomic Force Microscope (AFM), and X-ray photoelectron spectroscopy (XPS) were used for characterization of the interactive mechanism. The results may contribute to new insights into the transportation and environmental fate of $\mathrm{GO}$ in the aquatic environment.

\section{MATERIALS AND METHODS}

\section{Adsorption of GO}

At room temperature, macro-batch experiments were carried out on the adsorption and co-adsorption of GO on the LDH surface in $100 \mathrm{~mL}$ glass bottles. Simply put, add LDH suspension and GO stock solution to a glass bottle to obtain different components with specified concentrations. By adding a negligible $0.1 \mathrm{~mol} / \mathrm{L} \mathrm{HCl}$ and/or $\mathrm{NaOH}$ solution, the $\mathrm{pH}$ value of these interaction systems is adjusted in the range of 1.0-8.0. Similarly, a slight increase in the total volume of the interaction system has almost no obvious effect on the solid/liquid ratio. The interacting suspension is gently shaken for 6 hours to achieve adsorption equilibrium. The bottle is then left on a flat surface for 1.0 days to completely settle the large GO aggregate. Finally, LDH was separated from the solution by centrifugation at 18,000 RPM for 30 minutes.

The concentration of GO remaining in the supernatant was analysed with an ultraviolet-visible spectrophotometer (UV1800, chemical) at a wavelength of $210 \mathrm{~nm}$. To calculate the GO removal rate $\mathrm{R}$ and distribution coefficient $K_{d}$, the equations (1), (2) and (3) were used.

$$
\begin{gathered}
R=\frac{C_{0}-C_{e}}{C_{0}} \times 100 \% \\
Q_{e}=\frac{\left(C_{0}-C_{e}\right) \times V}{\mathrm{~m}} \\
K_{d}=\frac{Q_{\mathrm{e}}}{C_{e}}
\end{gathered}
$$

Where $C_{o}(\mathrm{mg} / \mathrm{L})$ and $C_{e}(\mathrm{mg} / \mathrm{L})$ are the initial and equilibrium concentrations of $\mathrm{GO}, Q_{e}$ is the amount of adsorption. Considering GO loss required for $\mathrm{LDH}$ adsorption (GO adsorption on glass bottle wall), calibration curves were obtained under the same conditions as the adsorption process, but without LDH. According to the calibration curve, the adsorption capacity of GO was calculated by subtracting the mass in solution from the added mass. To confirm the accuracy of data repeatability, experiments were carried out in duplicate, and each data were measured in triplicate. The relative error is less than 5\% (Wang et al. 2016, Zou et al. 2016).

\section{Materials}

All the chemicals used in the experiment were purchased from China Petroleum \& Chemical Corporation (Beijing, China). $\mathrm{Mg} / \mathrm{Al}$ layered double hydroxide (LDH) was prepared by the co-precipitation method (Chang et al. 2017, $\mathrm{Hu}$ et al. 2017). The graphene oxide aqueous solution was purchased from Suzhou Tanfeng Graphene Technology Co., Ltd. (Jiangsu, China).

\section{Characterization}

The crystal structure of the absorber was examined with X-ray diffractometer (XRD, Empyrean) using $\mathrm{Cu} \mathrm{K} \alpha$ radiation. The functional groups were identified by Fourier transform infrared spectroscopy (FTIR, NEXUS) with a scanning range of 400-4000 $\mathrm{cm}^{-1}$. Scanning electron microscope (SEM, JSM-6360LV), atomic force microscopy (AFM, SPA 400), and high-resolution transmission electron microscope (HRTEM, JEM-2100F) were used to study morphology and elemental composition of the synthetic materials. Thermo ESCALAB 250 performs X-ray photoelectron spectroscopy (XPS) spectroscopic analysis using a focused monochromatic Al Ka X-ray source $(\mathrm{hm}=1486.6 \mathrm{eV})$.

\section{RESULTS AND DISCUSSION}

\section{Characterization}

The surface morphology of the material can be observed from the scanning electron microscope (SEM) and transmission electron microscope (TEM) images. The results show that the LDH of hexagonal overlapping crystals is smooth and well-shaped (Fig. 1A and B). The GO agglomerates are multi-layered, with lateral dimensions ranging from a few nanometres to tens of nanometres $(\mathrm{C}$ and $\mathrm{D})$. Besides, The LDH/GO-pH $<7$ presents uneven morphology (Fig. 1E). Compared with LDH/GO-pH $<7$, the LDH/GO-pH $>7$ shows the characteristic of smooth surface and relative homogeneous flaky structure (Fig. 1 G). Besides, TEM images revealed 
the sheet-like structure of LDH/GO more clearly (Fig. 1 F). On the other hand, compared with GO and LDH before adsorption, after adsorption, TEM of LDH/GO adhered to black substance, with irregular shape and uneven thickness, indicating that GO adsorbed on LDH surface.
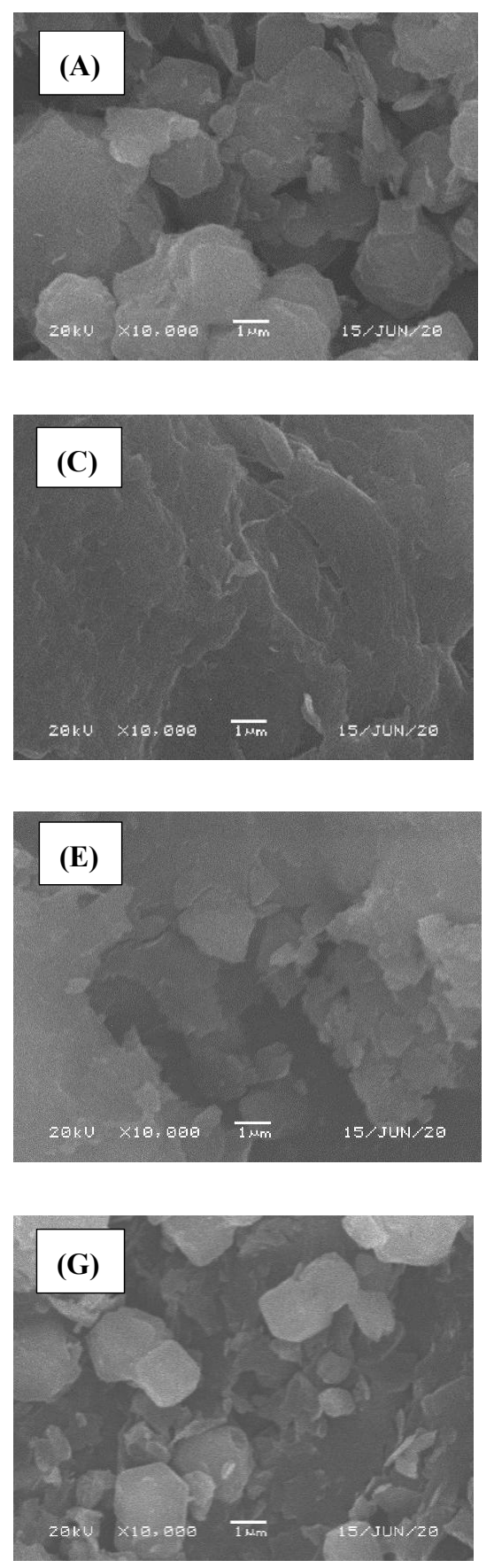

To reveal the adsorption mechanism, XRD technology was used to characterize the composite material. From the X-ray diffraction (XRD) pattern of GO (Fig. 2 a), a characteristic peak can be observed at $2 \theta=10.32$, indicating GO's (001) reflection. As shown in Fig. 2 compared with
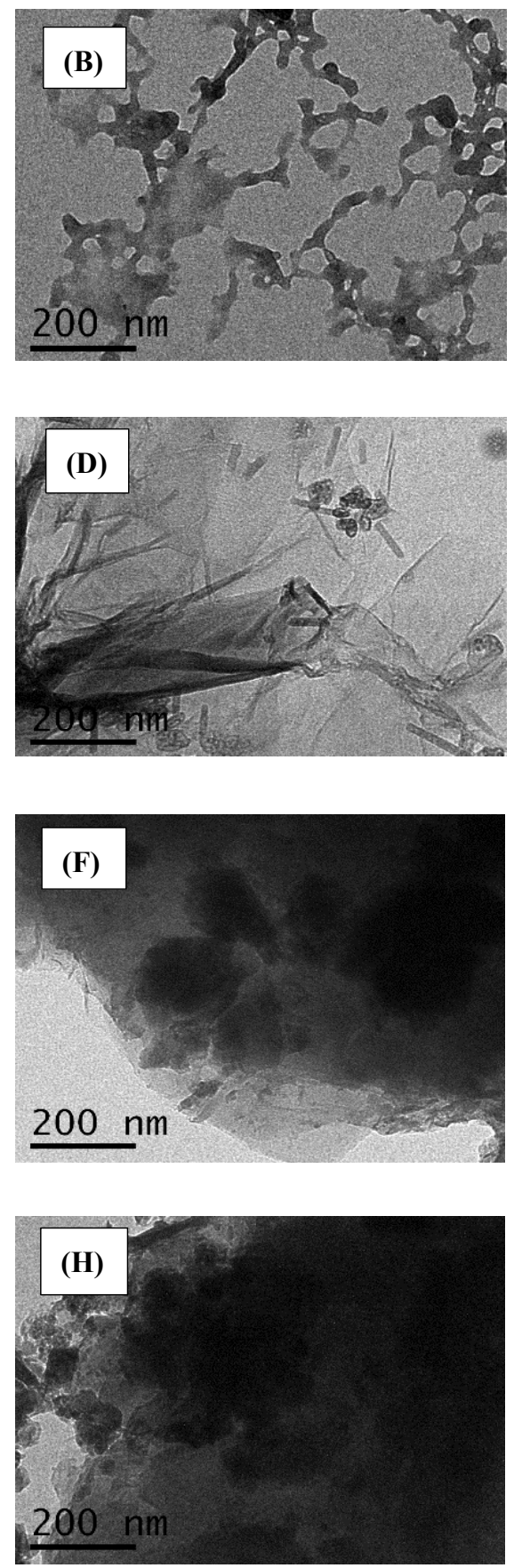

Fig. 1: SEM (A) and TEM (B) of LDH, SEM (C) and TEM (D) of GO, SEM (E) and TEM (F) of LDH-pH < 7, SEM (G) and TEM (H) of $\mathrm{LDH} / \mathrm{GO}-\mathrm{pH}>7$. 

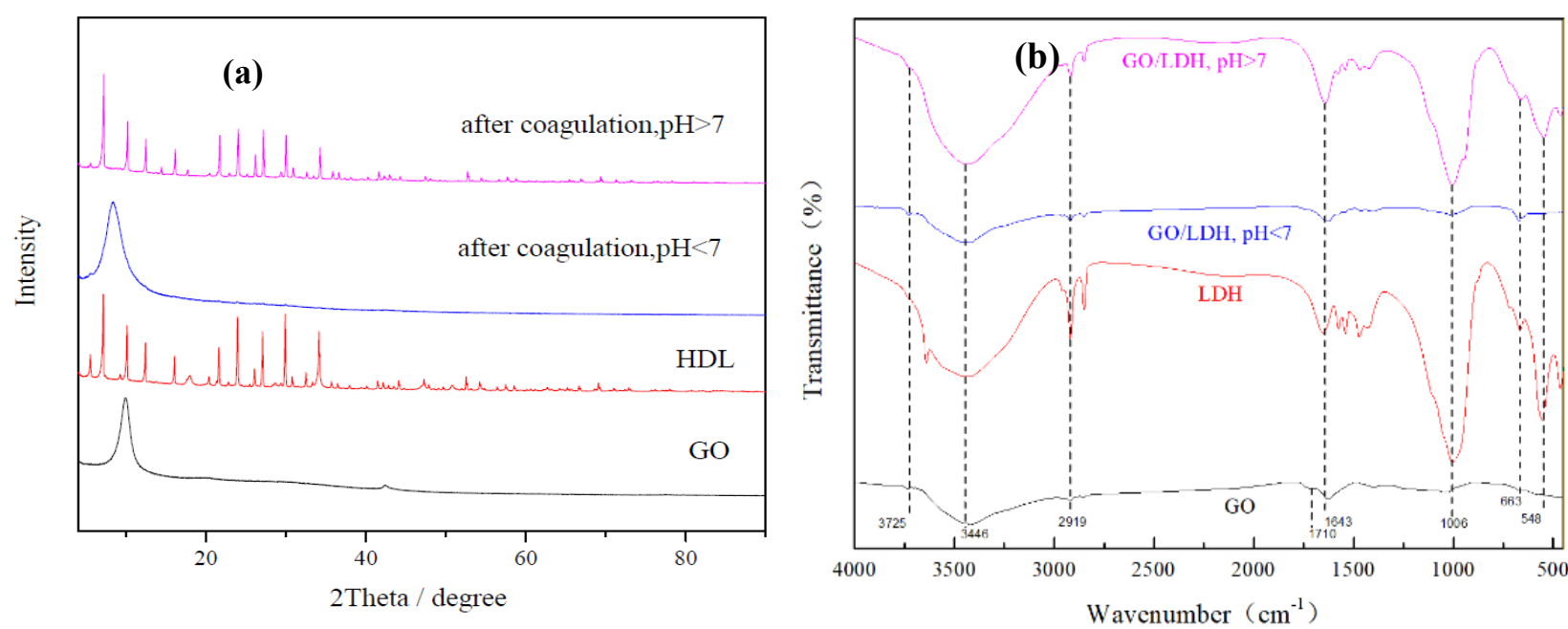

Fig. 2: XRD patterns (a) of GO, LDH, LDH-pH < 7, LDH/GO-pH > 7, FT-IR spectra (b) of GO, LDH, LDH-pH $<7$, LDH/GO-pH > 7.

the characteristic diffraction peaks of GO and LDH before adsorption, the characteristic diffraction peaks under acidic conditions are similar to $\mathrm{GO}$, indicating that $\mathrm{GO}$ adsorption under acidic conditions occurs on the surface of LDH. However, the characteristic diffraction peak under alkaline conditions is almost unchanged from that of LDH, which shows that there is no-GO aggregation on the surface of LDH under alkaline conditions.

FT-IR spectroscopy is very helpful for characterizing surface functional groups. As shown in Fig. 2 b, the band at $3500 \mathrm{~cm}^{-1}$ indicates the $\mathrm{O}-\mathrm{H}$ stretching mode, which involves hydrogen bonding or interlayer water molecules, the band at $\sim 1006 \mathrm{~cm}^{-1}$ is attributed to C-O group, the band at $\sim 1643 \mathrm{~cm}^{-1}$ is attributed to $\mathrm{C}=\mathrm{C}$ group, the band at $\sim 1710$ $\mathrm{cm}^{-1}$ is attributed to $\mathrm{C}=\mathrm{O}$ group, indicating the presence of an amount of oxygen-containing functional groups on GO. The broadband at $3446 \mathrm{~cm}^{-1}$ is attributed to the hydrogen bonding or the stretching mode of the $\mathrm{OH}$ group with the interlayer water molecules involved. The $\mathrm{C}=\mathrm{C}$ stretching vibration of GO shows the energy band in the energy range of $\sim 1643 \mathrm{~cm}^{-1}$ (Goh \& Lim 2010, Rao et al. 2005), which also appeared in the spectra of LDH/GO-pH $<7$ and LDH/ GO-pH $>7$, indicating that GO was successfully adsorbed on the surface of LDH.

\section{Effect of pH}

The adsorption of GO on non-specific and specific adsorbents depends on $\mathrm{pH} . \mathrm{pH}$ significantly affects the surface chemistry and adsorption chemistry of LDH-containing mixtures(González et al. 2014). The removal rate, removal efficiency, and distribution coefficient of GO on LDH as a function of $\mathrm{pH}$ are shown in Fig. 3. The removal of GO on
LDH was studied with a different $\mathrm{pH}$ value of $2,3,4,5,6$, 7,8 and 9 respectively shows that the removal capabilities are influenced by $\mathrm{pH}$ values. It can be seen from Fig. 3 that when $\mathrm{pH}<5$, as the $\mathrm{pH}$ increases, the removal rate and distribution coefficient of GO decreases rapidly, while when $\mathrm{pH}>5$, as the $\mathrm{pH}$ increases, the removal rate and distribution coefficient remains unchanged, $17.9 \%$ and 0.43 respectively. The maximum removal rate of GO by $\mathrm{LDH}$ is $93 \%$, which is due to the electrostatic action between the negative charge of $\mathrm{GO}$ and the positive charge of $\mathrm{LDH}$. At $\mathrm{pH}<5$, the main interaction is controlled by chemical adsorption, electrostatic attraction and hydrogen bonding. Because of electrostatic attraction, the negatively charged graphene oxide is easy to agglomerate and adsorb on positively charged LDH. However, at a $\mathrm{pH}$ above 5.0, by increasing the $\mathrm{pH}$ value, the carboxyl group on the GO group is deprotonated and inhibits the bonding and accumulation of cations and graphene oxide,

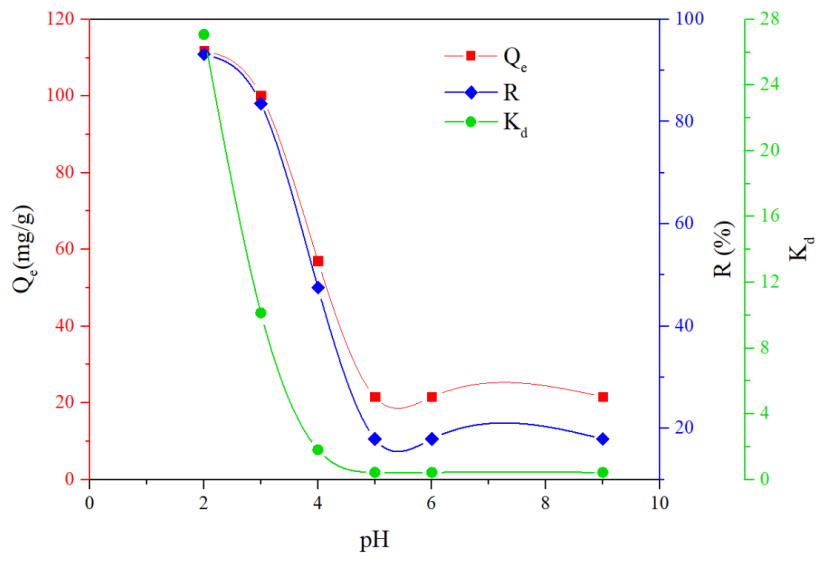

Fig. 3: Removal of GO on $\mathrm{LDH}$ as a function of $\mathrm{pH}$ value. 
thereby weakening the electron acceptor ability of these substances (Yang et al. 2013b). On the other hand, the GO carried when the $\mathrm{pH}$ value changes from 5 to 9 will cause the electrostatic repulsion between GO and LDH to increase, so the adsorption capacity decreases (Tang et al. 2020), and the main interaction is controlled by physical adsorption.

Therefore, it can be concluded that low $\mathrm{pH}$ facilitates the adsorption of GO by LDH and alkaline conditions will inhibit the adsorption of GO by the $\mathrm{LDH}$, which is the adsorption of $\mathrm{LDH}$ to $\mathrm{GO}$ is $\mathrm{pH}$-dependent, it is recommended to carry out the adsorption process at a $\mathrm{pH}$ close to strong acidity.

\section{Effect of Adsorbent Dosage}

Adsorption dosage is also one of the parameters which directly affects the removal of pollutants from aqueous solutions. The removal of GO on LDH was studied with different LDH content of $5,10,15,20$ and $25 \mathrm{mg}$, respectively shows the removal capabilities are influenced by LDH content. Fig. 4 shows the effect of LDH content on adsorption capacity, efficiency and distribution coefficient. In the solution with $\mathrm{pH} 3.0$ and $\mathrm{GO}=100 \mathrm{mg} / \mathrm{L}$, the $\mathrm{LDH}$ content was changed to $5-25 \mathrm{mg}$, the equilibrium time was $6 \mathrm{~h}$, and the corresponding tests were carried out. It can be seen from the figure that as the LDH content increases, the removal rate gradually decreases and tends to $0 \%$. Similarly, the adsorption amount and distribution coefficient are also oriented to 0 . This shows that, while maintaining GO concentration to a certain extent, adding LDH can greatly decrease the adsorption capacity of $\mathrm{LDH}$. It shows that LDH has high coagulation ability at low concentration, which is crucial for the application of LDH in the coagulation treatment of GO in aqueous solution.

When the content of LDH increased from $5 \mathrm{mg}$ to $15 \mathrm{mg}$, the adsorption ability decreased, although the removal rate

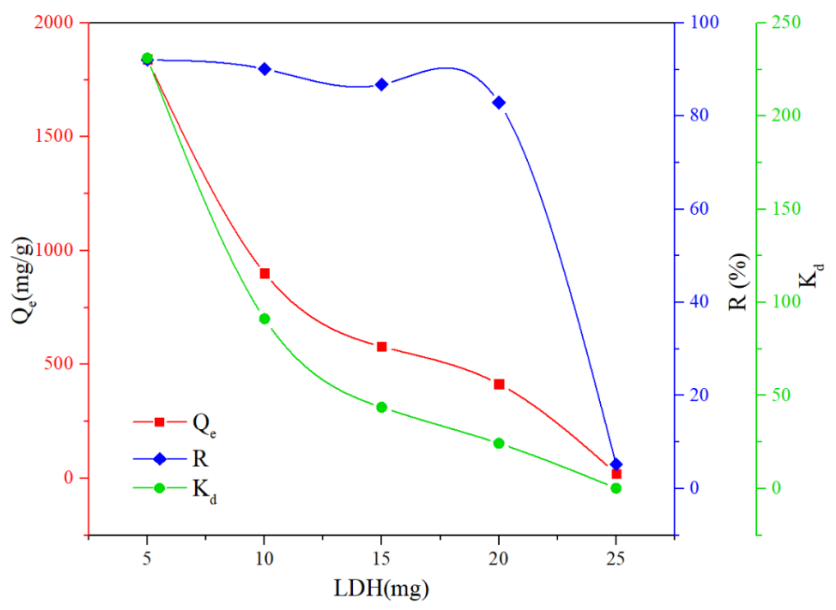

Fig. 4: Removal of GO on LDH as a function of LDH contents. of GO was maintained. This was because the adsorption sites in aqueous solution increased with the increase of the LDH, the concentration of adsorption sites with higher energy may lead to the reduction of active sites with lower energy, resulting in the reduction of adsorption (Zubair et al. 2017). Therefore, reducing the amount of $\mathrm{LDH}$ can not only improve the removal rate of $\mathrm{GO}$ in the aqueous solution but also save costs.

\section{Effect of GO Initial Concentration}

The removal of GO on LDH were studied with different GO initial concentrations of 20,40,60, 80, 100, 120, 140 and $160 \mathrm{mg} / \mathrm{L}$, respectively. The result demonstrates the removal capabilities are influenced by GO initial concentrations. Fig. 5 shows the effect of GO concentration on adsorption capacity, efficiency, and distribution coefficient. In the solution with $\mathrm{pH} 3.0$ and $\mathrm{LDH}=10 \mathrm{mg}$, the $\mathrm{GO}$ concentration was changed to $20-160 \mathrm{mg} / \mathrm{L}$, the equilibrium time was $6 \mathrm{~h}$, and the corresponding tests were carried out. There is little difference at GO initial concentration less than $60 \mathrm{mg} / \mathrm{L}$, maintain at $60 \%$. However, it can be seen from the Fig. 5 that as the GO concentration increases, the removal rate gradually increases and tends to $92 \%$, the fastest rising stage is within the range of $60-100 \mathrm{mg} / \mathrm{L}$, there is a similar trend in adsorption amount and distribution coefficient. This shows that, while maintaining LDH to a certain extent, adding GO can greatly improve the adsorption capacity of $\mathrm{LDH}$, this may be due to the increased GO concentration increasing the electrostatic interaction with $\mathrm{LDH}$.

Therefore, between the above description, LDH has great potential for the adsorption of GO in aqueous solution. Due to the limitation of the experimental conditions, the maximum adsorption amount of GO for further research is still needed.

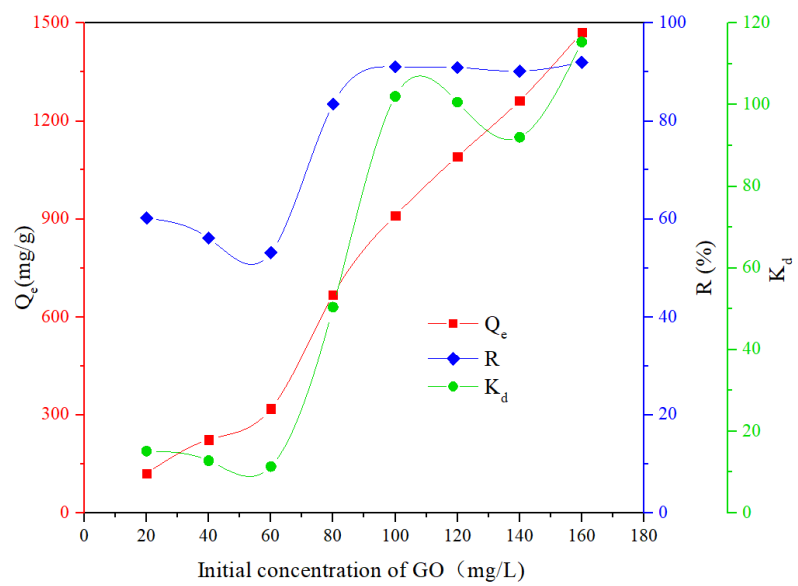

Fig. 5: Removal of GO on LDH as a function of GO contents. 


\section{Adsorption Mechanism}

To further explore the adsorption mechanism of LDH to $\mathrm{GO}$, the $\mathrm{LDH} / \mathrm{GO}$ solution of $\mathrm{pH}=3$ was analysed by XPS and AFM, and the results are shown in Fig. 6 and Fig. 7. As shown in Fig. 6 (a), various strong peaks can be observed, such as $\mathrm{Al}$ 2p, Mg 1s, Ca 2p, S2p, O 1s, C 1s. From the C $1 \mathrm{~s}$ high-resolution spectra before and after the adsorption of $\mathrm{GO}$, the $\mathrm{C} 1$ spectral deconvolution can be divided into three components, which are about $284.7 \mathrm{eV}, 285.8 \mathrm{eV}$, and $289.3 \mathrm{eV}$, respectively. However, after the adsorption and condensation of GO, the strength and position of the $\mathrm{C} 1 \mathrm{~s}$ component of LDH/GO changed obviously. Compared with that before the adsorption of GO, the relative area of $\mathrm{C}-\mathrm{O}$ and $\mathrm{O}-\mathrm{C}=\mathrm{O}$ assigned to $\mathrm{LDH} / \mathrm{GO}$ after $\mathrm{GO}$ adsorption increased significantly, and the peak position of $\mathrm{O}-\mathrm{C}=\mathrm{O}$ changed from $289.3 \mathrm{eV}$ to $287.8 \mathrm{eV}$. The interaction between $\mathrm{GO}$ and $\mathrm{LDH}$ is carried out by $\mathrm{C}-\mathrm{O}$ and $\mathrm{O}-\mathrm{C}=\mathrm{O}$ during the coagulation process. From the height of the AFM image and its corresponding morphology, the thickness of GO is $2.78 \mathrm{~nm}$, and the thickness of $\mathrm{LDH} / \mathrm{GO}$ is $3.89 \mathrm{~nm}$, which indicates that GO is adsorbed on the surface of $\mathrm{LDH}$, which is consistent with the TEM results. Based on the above analysis, it is shown that through the condensation of GO on the surface of LDH, LDH can effectively remove GO.
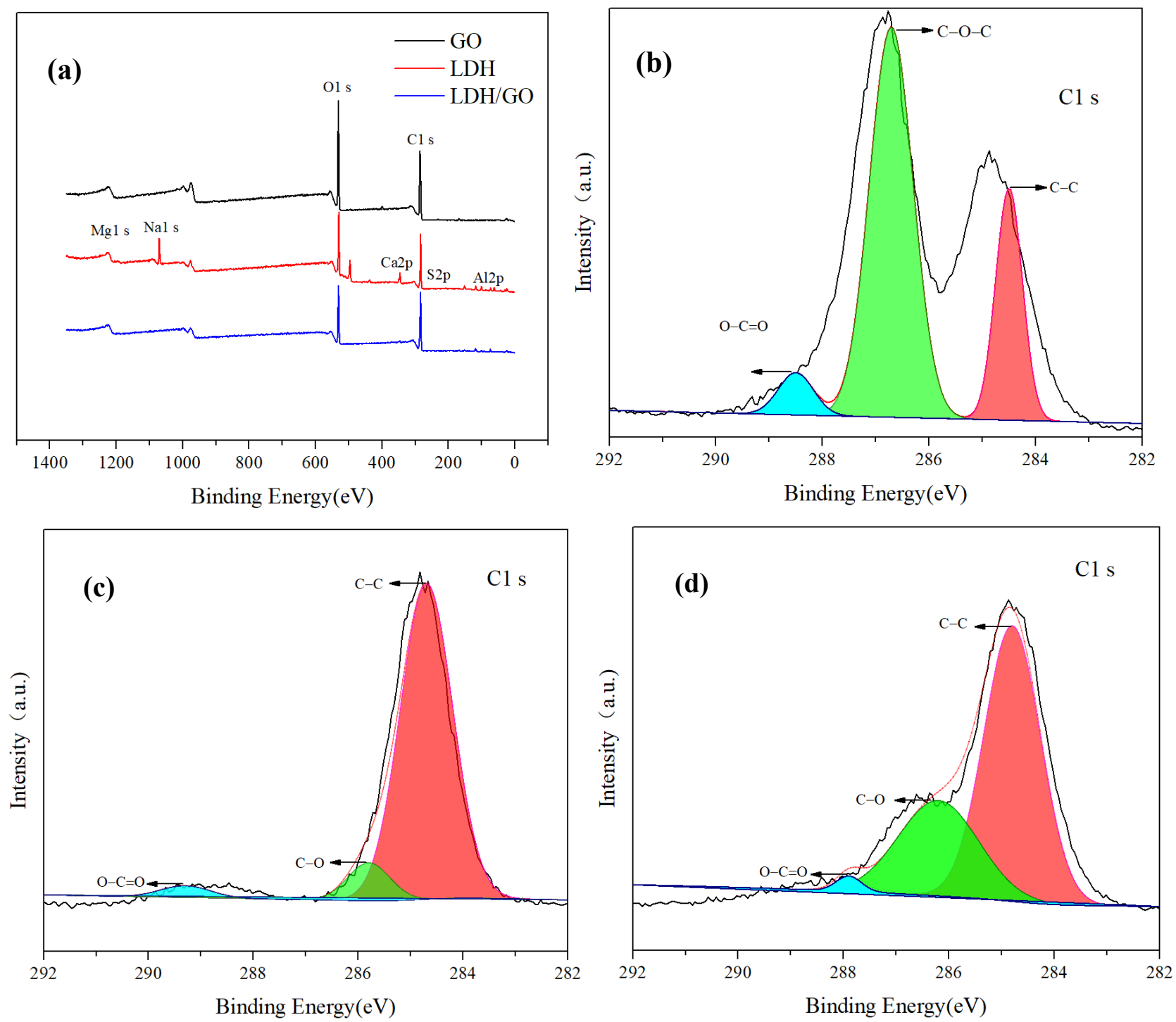

Fig. 6: XPS spectra of LDH/GO before and after GO removal (a), the high C 1s deconvolution of GO (b), before (c), and after (d) GO coagulation on $\mathrm{LDH} / \mathrm{GO}$. 

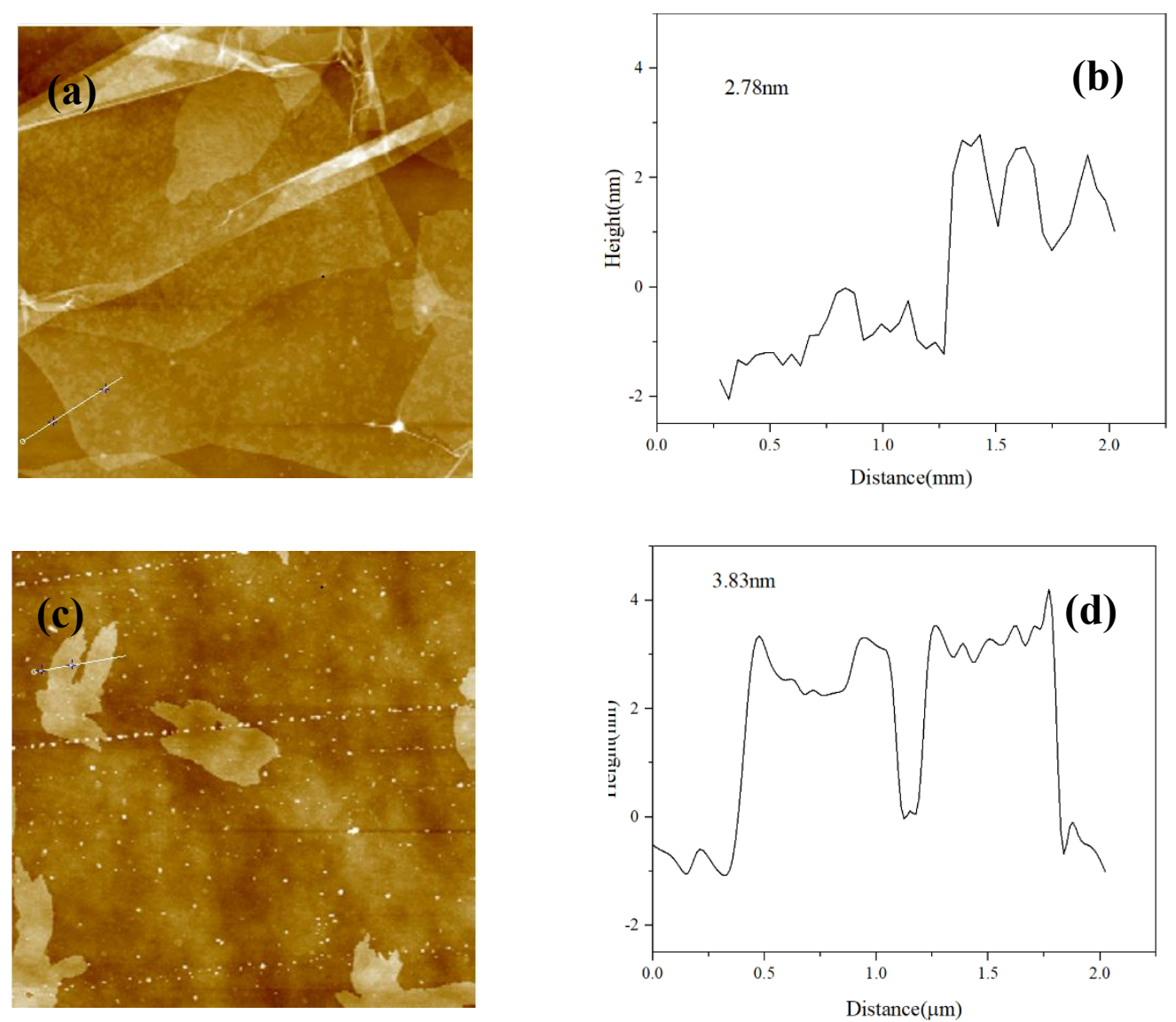

Fig. 7: AFM image and the corresponding height profiles of GO (a) (b)and LDH/GO (c) (d).

\section{CONCLUSION}

With the rapid development and wide application of GO products, it is inevitable to release them into the natural environment. Therefore, the rapid coagulation of GO is particularly important and urgent due to its high activity and toxicity in the environment. Here, we found that LDH can effectively remove GO from the aqueous solution and came to some meaningful conclusions: The significant change in GO removal indicates that the coagulation behaviour is $\mathrm{pH}$ dependent. Its adsorption capacity depends largely on the $\mathrm{pH}$ of the solution, $\mathrm{LDH}$ content, and GO content, the maximum removal rate of GO by $\mathrm{LDH}$ can reach $92 \%$, the adsorption capacity can reach $1472 \mathrm{mg} / \mathrm{g}$. On the other hand, XPS spectroscopy has been fully studied, the interaction between $\mathrm{GO}$ and $\mathrm{LDH}$ is carried out by $\mathrm{C}-\mathrm{O}$ and $\mathrm{O}-\mathrm{C}=\mathrm{O}$ during the coagulation process.

In a word, LDH material has high condensation ability to $\mathrm{GO}$ in aqueous solution, which indicates that LDH material can be a promising material to effectively remove GO from aqueous solution by simple and rapid chemical condensation. Therefore, the results of this work may contribute to a better understanding of the condensation behaviour of $\mathrm{GO}$ and other carbon-based materials in natural and engineering aqueous solutions, which is essential for eliminating GO in aqueous solutions and reducing the environmental toxicity of GO in natural environments.

\section{REFERENCES}

Awad, F. S., Abou Zied, K. M., Abou El-Maaty, W. M., El-Wakil, A. M. and Samy El-Shall, M. 2020. Effective removal of mercury (II) from aqueous solutions by chemically modified graphene oxide nanosheets. Arabian Journal of Chemistry. 13(1): 2659-2670.

Azadian, E., Arjmand, B., Ardeshirylajimi, A., Hosseinzadeh, S., Omidi, M. and Khojasteh, A. 2020. Polyvinyl alcohol modified polyvinylidene fluoride-graphene oxide scaffold promotes osteogenic differentiation potential of human induced pluripotent stem cells. J. Cell. Biochem., 121(5-6): 3185-3196.

Bao, S., Yang, W., Wang, Y., Yu, Y. and Sun, Y. 2020. One-pot synthesis of magnetic graphene oxide composites as an efficient and recoverable adsorbent for $\mathrm{Cd}(\mathrm{II})$ and $\mathrm{Pb}(\mathrm{II})$ removal from aqueous solution. J. Hazard Mater., 381: 120914. 
Baragaño, D., Forján, R., Welte, L. and Gallego, J.L.R. 2020. Nanoremediation of As and metals polluted soils by means of graphene oxide nanoparticles. Scientific Reports, 10(1).

Batista de Melo, C., Coa, F., Alves, O. L., Martinez, D. S. T. and Barbieri, E. 2019. Co-exposure of graphene oxide with trace elements: Effects on acute ecotoxicity and routine metabolism in Palaemon pandaliformis (shrimp). Chemosphere, 223: 157-164.

Chang, K., Sun, Y., Ye, F., Li, X., Sheng, G., Zhao, D., Linghu, W., Li, H. and Liu J. 2017. Macroscopic and molecular study of the sorption and co-sorption of graphene oxide and $\mathrm{Eu}(\mathrm{III})$ onto layered double hydroxides. Chemical Engineering Journal, 325: 665-671.

Duru, ., Ege, D. and Kamali, A. R. 2016. Graphene oxides for removal of heavy and precious metals from wastewater. Journal of Materials Science, 51(13): 6097-6116.

Gao, Y., Ren, X., Zhang, X. and Chen, C. 2019. Environmental fate and risk of ultraviolet- and visible-light-transformed graphene oxide: A comparative study. Environ. Pollut., 251: 821-829.

Goh, K. H. and Lim, T. T. 2010. Influences of co-existing species on the sorption of toxic oxyanions from aqueous solution by nanocrystalline Mg/Al layered double hydroxide. J. Hazard. Mater., 180(1-3): 401-408.

González, M. A., Pavlovic, I., Rojas-Delgado, R. and Barriga C. 2014. Removal of $\mathrm{Cu}^{2+}, \mathrm{Pb}^{2+}$, and $\mathrm{Cd}^{2+}$ by layered double hydroxide-humate hybrid. Sorbate and sorbent comparative studies. Chemical Engineering Journal, 254: 605-611.

Hu, B., Huang, C., Li, X., Sheng, G., Li, H., Ren, X., Ma, J., Wang, J. and Huang, Y. 2017. Macroscopic and spectroscopic insights into the mutual interaction of graphene oxide, $\mathrm{Cu}(\mathrm{II})$, and $\mathrm{Mg} / \mathrm{Al}$ layered double hydroxides. Chemical Engineering Journal, 313: 527-534.

Liang, S., Xu, S., Zhang, D., He, J. and Chu, M. 2015. Reproductive toxicity of nanoscale graphene oxide in male mice. Nanotoxicology, 9(1): 92-105.

Liu, Y., Yang, D., Xu, T., Shi, Y., Song, L. and Yu, Z.Z. 2020. Continuous photocatalytic removal of chromium (VI) with structurally stable and porous $\mathrm{Ag} / \mathrm{Ag}_{3} \mathrm{PO}_{4} /$ reduced graphene oxide microspheres. Chemical Engineering Journal, 379: 122200.

Paital, B., Guru, D., Mohapatra, P., Panda, B., Parida, N., Rath, S., Kumar, V., Saxena, P. S. and Srivastava A. 2019. Ecotoxic impact assessment of graphene oxide on lipid peroxidation at mitochondrial level and redox modulation in freshwater fish Anabas testudineus. Chemosphere, 224: 796-804.

Pang, H., Wu, Y., Wang, X., Hu, B. and Wang, X. 2019. Recent advances in composites of graphene and layered double hydroxides for water remediation: a review. Chemistry-An Asian Journal, 14(15): 2542-2552.

Rao, M. M., Reddy, B. R., Jayalakshmi, M., Jaya, V. S. and Sridhar, B. 2005. Hydrothermal synthesis of $\mathrm{Mg}$ - $\mathrm{Al}$ hydrotalcites by urea hydrolysis. Materials Research Bulletin, 40(2): 347-359.

Song, S., Yin, L., Wang, X., Liu, L., Huang, S., Zhang, R., Wen, T., Yu, S., Fu, D., Hayat, T. and Wang, X. 2018. Interaction of U(VI) with ternary layered double hydroxides by combined batch experiments and spectroscopy study. Chemical Engineering Journal, 338: 579-590.
Tang, H., Zhang, S., Huang, T., Cui, F. and Xing, B. 2020. pH-dependent adsorption of aromatic compounds on graphene oxide: An experimental, molecular dynamics simulation and density functional theory investigation. Journal of Hazardous Materials, 395: 122680.

Wang, J., Wang, X., Tan, L., Chen, Y., Hayat, T., Hu, J., Alsaedi, A., Ahmad, B., Guo, W. and Wang, X. 2016. Performances and mechanisms of Mg/ $\mathrm{Al}$ and $\mathrm{Ca} / \mathrm{Al}$ layered double hydroxides for graphene oxide removal from aqueous solution. Chemical Engineering Journal, 297: 106-115.

Wang, X., Yu, S., Wu, Y., Pang, H., Yu, S., Chen, Z., Hou, J., Alsaedi, A., Hayat, T. and Wang, S. 2018. The synergistic elimination of uranium (VI) species from aqueous solution using bi-functional nanocomposite of carbon sphere and layered double hydroxide. Chemical Engineering Journal, 342: 321-330.

Wu H.Y., Li, S.T., Shao, Y.W., Jin, X.Z., Qi, X.D., Yang, J.H., Zhou, Z.W. and Wang, Y. 2020. Melamine foam/reduced graphene oxide supported form-stable phase change materials with simultaneous shape memory property and light-to-thermal energy storage capability. Chemical Engineering Journal, 379: 122373.

Xing, M., Zhuang, S. and Wang, J. 2020. Efficient removal of Cs(I) from aqueous solution using graphene oxide. Progress in Nuclear Energy, 119: 103167

Yang, D., Song, S., Zou, Y., Wang, X., Yu, S., Wen, T., Wang, H., Hayat, T., Alsaedi, A. and Wang, X. 2017. Rational design and synthesis of monodispersed hierarchical $\mathrm{SiO}_{2} @$ layered double hydroxide nanocomposites for efficient removal of pollutants from aqueous solution. Chemical Engineering Journal, 323: 143-152.

Yang, K., Li, Y., Tan, X., Peng, R. and Liu, Z. 2013a. Behavior and toxicity of graphene and its functionalized derivatives in biological systems. Small, 9(9-10): 1492-1503.

Yang, Z., Yan, H., Yang, H., Li, H., Li, A. and Cheng, R. 2013b. Flocculation performance and mechanism of graphene oxide for removal of various contaminants from water. Water Res., 47(9): 3037-3046.

Yu, C., Shao, J., Sun, W. and Yu, X. 2020. Treatment of lead contaminated water using synthesized nano-iron supported with bentonite/graphene oxide. Arabian Journal of Chemistry, 13(1): 3474-3483.

Yu, S., Wang, X., Chen, Z., Wang, J., Wang, S., Hayat, T. and Wang X. 2017. Layered double hydroxide intercalated with aromatic acid anions for the efficient capture of aniline from aqueous solution. Journal of Hazardous Materials, 321: 111-120.

Zhang, Z., Liu, X., Wu, J., Ren, X. and Li, J. 2020. Insight into the removal of graphene oxide by nanoscale zero-valent iron. Journal of Molecular Liquids, 314: 113553.

Zou, Y., Wang, X., Ai, Y., Liu, Y., Li, J., Ji, Y. and Wang, X. 2016. Coagulation behavior of graphene oxide on nanocrystallined $\mathrm{Mg} / \mathrm{Al}$ layered double hydroxides: Batch experimental and theoretical calculation study. Environ. Sci. Technol., 50(7): 3658-3667.

Zubair, M., Daud, M., McKay, G., Shehzad, F. and Al-Harthi, M. A. 2017. Recent progress in layered double hydroxides (LDH)-containing hybrids as adsorbents for water remediation. Applied Clay Science, 143: 279-292. 